\title{
NEGRITUD Y GÉNERO: LA REPRESENTACIÓN DE LA MUJER NEGRA EN LA LITERATURA DECIMONÓNICA ARGENTINA
}

\author{
Djibril Mbaye \\ Universidad Cheikh Anta Diop de Dakar (Senegal) \\ djibrilmbaye2000@yahoo.fr
}

\begin{abstract}
RESUMEN: Este trabajo se propone analizar la representación que se hace de la mujer negra en los escritos fundacionales de la literatura argentina del siglo XIX. Considerada como un sujeto subalterno y doblemente discriminado por su color y por su feminidad, la mujer negra viene retratada desde el ámbito político y social. José Mármol, Esteban Echeverría y José Hernández nos describen en Amalia, El Matadero y Martín Fierro a una figura femenina delatora y animalizada. Así, en este artículo, presentaremos primero el panorama sociohistórico y político de la condición negra y femenina en Argentina y analizaremos después, por obra, la imagen y protagonismo de la mujer negra.

PALABRAS CLAVE: negritud, género, literatura, antirrosismo, Argentina.
\end{abstract}

\section{NEGRITUD AND GENDER: THE REPRESENTATION OF BLACK WOMAN IN THE NINETEENTH-CENTURY ARGENTINE LITERATURE}

\begin{abstract}
This work proposes to analyse the representation of the black woman in the foundational narratives of argentine literature. Considered like a subaltern subject and doubly discriminated for his colour and his femininity, the black woman is painted from politic and social area. José Mármol, Esteban Echeverría and José Hernández in Amalia, El matadero and Martín Fierro describe a feminine figure whistle-blower and animalised. Then, in this paper, we will present first the sociohistorical and political panorama of black and feminine condition and after analyse, for work, the image and the protagonism of the black woman.
\end{abstract}

KEYWORDS: negritud, gender, literature, antirrosism, Angentine. 


\title{
NEGRITUD ET GENRE: LE REPRESENTATION DE LA FEMME NOIRE DANS LA LITTÉRATURE ARGENTINE DU XIX SIECLE
}

\begin{abstract}
RESUMÉ: L'objectif de ce travail est d'analyser la représentation faite de la femme noire dans les récits fondateurs de la littérature argentine du XIX siècle. Considérée comme un sujet subalterne et doublement discriminé par la couleur de sa peau et sa féminité, la femme noire est peinte depuis la sphère politique et sociale. José Mármol, Esteban Echeverría et José Hernández nous décrivent dans Amalia, El matadero et Martín Fierro une figure féminine délatrice et animalisée. Ainsi, dans cet article, nous présenterons d'abord le panorama sociohistorique et politique de la condition noire et féminine en Argentine avant d'analyser, par ouvre, l'image et le protagonisme de la femme noire.
\end{abstract}

MOTS CLÉS : négritude, genre, littérature, antirrosisme, Argentine.

Recibido: 3/12/2018. Aceptado: 14/05/2019

\section{Introducción}

La presencia de lo africano en Latinoamérica, cifrada principalmente en el concepto de lo negro, se originó en la atroz sangría que conoció el continente durante la infamante trata de negros. En la cartografía de esta presencia, se suele situar el epicentro en las regiones caribeña y antillana. Sin embargo, otros focos importantes de población negra residieron en otras partes del continente, como en el Cono Sur, particularmente en Argentina, que ha sido protagonista de una llegada masiva y de grandes asentamientos de esclavos. Pero hoy apenas se le menciona (en peso demográfico) cuando se habla de presencia de afrodescendientes en el continente americano, un hecho que no es una casualidad sino que tiene todo su fundamento histórico.

Si hoy en el pensamiento común argentino los negros son "invisibles", en el siglo XIX sí que formaron un núcleo demográfico significante, por lo que queremos saber cómo era su representación en las letras de aquél entonces, en otros términos, qué papel han desempeñado en la literatura de dicho siglo (como personajes) y qué imágenes reflejan en el imaginario colectivo nacional. Siendo la literatura un testimonio a la vez explícito e implícito de la historia, la presencia de personajes negros en las narraciones canónicas decimonónicas 
puede enterarnos de la representación social de esa clase considerada a menudo como subordinada.

Ahora bien, este artículo se quiere más preciso y se propone mostrar la representación de la mujer negra a través de las obras más distintivas de la literatura decimonónica argentina como Martín Fierro de José Hernández, Amalia de José Mármol y El matadero de Esteban Echeverría. Siendo la mujer negra víctima de su doble condición subalterna, por el color y por el género, y siendo también una olvidada de la Historia, su presencia en la literatura puede ser una pestaña desde la cual se perciben su imagen y su protagonismo en una sociedad europeizante (blanca y blanqueadora) y patriarcal.

Así, nuestro objeto es estudiar el sitio y la situación de la mujer negra a través de los relatos fundadores de la nación argentina. Es un tema, hasta mediados del siglo pasado, poco debatido pero que hoy, con el auge de las llamadas corrientes feministas y de los movimientos afrodescendientes, está cobrando una gran importancia. Este artículo viene a sumarse a los trabajos de rescate de la memoria de esas minorías olvidadas. En una primera parte hablaremos de la re-presentación problemática del negro en general y de la mujer en particular en la sociedad argentina, y después analizaremos la presencia de los personajes femeninos de color en los textos citados.

\section{Una presencia y una existencia problemáticas}

En la Argentina de hoy, la historia del negro parece resumirse en unas frases como: "no hay...", "hay muy pocos...", "no se ven..." (Lobeiro 1999). La pregunta que se hace todo el mundo acerca de la "desaparición" de los negros es la que Ildefonso Pereda Valdés expresa de la manera siguiente: “¿Cómo se explica sino que en la época de Rosas una tercera parte de la población de Buenos Aires era morena y existían barrios negros como el del Tambor y el del Mondongo, y hoy es raro encontrar negros en Buenos Aires?” (1978: 459).

En efecto, Argentina se ha convertido en uno de los países hispanoamericanos donde se encuentran menos afrodescendientes. No obstante, es unánime entre los historiadores que, en época de la gobernación de Juan Manuel de Rosas (18291852), el $30 \%$ de la población de Buenos Aires era negra. En otras grandes ciudades, en el período colonial, la población negra incluso superaba a la de las demás comunidades ${ }^{1}$.

1. Miriam Victoria Gomes (2002) da algunas cifras de la presencia de negros en el período colonial 
Ahora bien, el fulgurante decrecimiento de la población negra tiene, antes que nada, un fundamento ideológico. En efecto, en la Argentina postcolonial, la cuestión de la identidad fue la espina dorsal de la construcción de la Nación. $\mathrm{Y}$ en eso, los intelectuales, de casi todos los bandos, han abogado por una argentina blanca y europea en la que la extirpación de la estirpe indígena (negra en particular) era uno de los requisitos. De la acuñación de la famosa fórmula "Civilización y Barbarie" por Sarmiento (quien festejaba el bajísimo número de negros en el país), para fundamentar esa ideología eurocentrista, a la declaración del presidente Carlos Menem en 1993 de que "en Argentina no hay negros", ha habido una voluntad manifiesta de negación de la afroargentinidad. Es en este sentido que reconoce Alejandro Solomianski que "los intelectuales argentinos, aún los más contestatarios, revolucionarios, progresistas o izquierdistas han absorbido dentro de sus esquemas perspectivos la operativa simbólica básica de la negación o invisibilidad de lo afroargentino" (2003: 119).

Uno de los requisitos del desarrollo y de la civilización era el "blanqueamiento" del país, que supone una extirpación de la semilla de la barbarie. Así, la creación de ese mito de la Argentina blanca ${ }^{2}$ presentará la urgencia de proponer el exterminio del indígena y el ocultamiento del negro, como representantes de la barbarie que componían parte de la realidad argentina (Yao 2002).

Esa ansia de europeización, de progreso y de civilización fue acompañada por una inmigración masiva de europeos (italianos, ingleses, alemanes, españoles, franceses...). De este modo, progresar era salir de América para entrar en Europa y por tanto la insistencia de la negación del indio y del negro. Esa pauta histórica provocó un método que se hizo norma que fue sustituir a los afroargentinos por los inmigrantes europeos (Yao 2002).

En esa creación de una nueva identidad postcolonial, "los grandes relatos fundacionales de la nacionalidad argentina ('blanca') se delineaban recortándose contra, o en contrapunto con, masas o individualidades negras" (Solomianski 2003: 18), y los términos "desaparición" e "invisibilización" de los negros constituyen

\footnotetext{
y observa que los datos del periodo colonial revelan lo siguiente: en el censo de 1778, se consigna que en el noreste argentino, en la zona de Tucumán, el 42\% de la población era negra; en Santiago de Estero la proporción era de 54\%; en Catamarca, para esa misma época el porcentaje de la población negra era del 52\%; en Salta, el 46\%; en Córdoba, el 44\%; en Mendoza, el 24\%; en La Rioja, el 20\%; en San Juan, el $16 \%$.

2. Ese mito de país blanco lleva Jean Touchard a llamar a Argentina "el país blanco en el sur de Canadá", mostrando así que en el continente americano es el segundo país blanco. En su obra, también se hace algunas preguntas que reflejan dicha idea: "l'Argentine est-elle le pays le moins américain de l'Amérique? Est-elle une annexe de l'Europe dans l'hémisphère Sud?" (1967: 7).
} 
sólo retóricas discursivas de ocultamiento apoyadas por una historiografía oficial que "ha omitido el aporte de la población de origen africano a la identidad Argentina" (Yao 2016: 22). El desempeño de los afrosoldados en todas las contiendas bélicas por la soberanía del país tanto en la artillería como en la infantería (Goldberg 2010) no ha servido para valorar su aporte a la construcción de la nación y restaurar una imagen manchada por la esclavización. Es en este sentido que reconoce también Ângela Corrêa (2006) que la historia oficial argentina, tan pródigamente esparcida en enciclopedias, en discursos y feriados nacionales, en actos solemnes y ofrendas florales, a menudo, para no decir siempre, ha olvidado restituir su lugar de destaque y de reconocimiento inobjetables a grandes sectores de la sociedad y de la cultura como el componente de origen africano dentro de su población y a los fundamentales aportes y contribuciones de este grupo. Más tajante ha sido Alejandro Frigerio quien considera que la existencia de un número importante o visible de negros, así como el reconocimiento de que tuvieron un rol de determinada importancia en la historia, va absolutamente en contra de la narrativa dominante de la historia, ya sea la oficial como la popular, y en contra del sentido común (2006: 81).

Hemos presentado este panorama para mostrar cómo la representación del negro en el ámbito literario será condicionada por esa cosmovisión sociopolítica e histórica. Sujeto subalterno ${ }^{3}$, su aparición en los textos canónicos deja ver

3. Los Estudios subalternos han marcado profundamente las ciencias sociales en ese final de siglo XX. Pero las lecturas y relecturas, que han desglosado diferentes versiones de la subalternidad (Pablo Alabarces 2016), han terminado por crear un torbellino crítico que ha complejizado mucho el concepto de "lo subalterno". De la relación de "hegemonía y dominancia" de Gramci al Subalternismo des/postcolonial latinoamericano (animado por los primeros pensadores como John Beverly, Robert Carr, etc. y los segundos como W. Mignolo, G. Williams, etc.) pasando por el subalterismo asiático protagonizado por Rajanit Guha y Gayatri Chakravorty Spivak (1988), con su concepto de "subordinación", el acercamiento al concepto de "lo subalterno" ha desembocado en senderos bifurcados. Nosotros usamos este concepto en el sentido de "rango inferior", "subordinación" social y política en una Argentina decimonónica que se había convertido en una miniatura de la relación Centro/Periferia. Nuestra concepción discurre entre estas dos posiciones de Gareth Williams y de Juan Zeballos.

En el subalternismo latinoamericano, Gareth William (2002) dice: “...entiendo la categoría de subalternidad en los términos articulados por Guha y Spivak. La considero como el a menudo violento efecto-de-sujeto de los procesos nacionales y postnacionales de subordinación social, pero también como el límite epistemológico en el cual lo no-hegemónico anuncia los límites del pensar hegemónico y del pensamiento hegemónico. En mi uso del término...no hay resolución a la relación entre las definiciones de Guha y de Spivak. No se privilegia una definición sobre la otra. Simplemente me aproximo a la cuestión de la subalternidad como el sitio de tensión práctica y teórica entre la historia materialista y la filosofía desconstructivista.".(http://www.ihnca.edu.ni/files/doc/ileana/).

La ejemplificación de Juan Zevallos es la más sencilla y comprensible. Sostiene "que [los] inmigrantes tienen una posición subalterna. La subalternidad de los inmigrantes andinos radica en el hecho de que la mayoría de ellos carecen o disfrutan de un nivel mínimo de trabajo, vivienda, alimentación y escolarización para alcanzar un bienestar humano" (http://www.ihnca.edu.ni/files/doc/ileana/). 
una imagen negativa. Ahora bien, tratándose de la mujer negra, su retrato era todavía más despectivo. La feminidad conjugada al color hacía de ella un ente sistemáticamente marginado. Pero para comprender esta marginación por el género, hay que escrutar primero el contexto sociopolítico e histórico no sólo de Argentina y de Latinoamérica sino de la época en general. La cuestión del "género" ha sido uno de los grandes combates ideológicos de las mujeres en los dos siglos pasados y hoy la teoría feminista se ha convertido en un tema ineludible en las tribunas sociales y políticas.

En efecto, el siglo XIX construyó una sociedad profundamente marcada por un patriarcalismo en el que la voz y el sitio de la mujer estaban confinados en el hogar. Para Mary Nash, la condición de la mujer se resumía en perfecta casada y ángel del hogar y a finales del siglo XIX y comienzos del XX, la representación cultural dominante sobre las mujeres se basaba en el discurso de la domesticidad que evocaba el prototipo femenino de la perfecta casada, cuyo rol primordial era el cuidado del hogar y la familia (1999: 25). Marcela Lagarde parte aún más lejos y extiende más la problemática con la declaración de los Derechos del Hombre de 1789 para quién, ya en su título, fomenta la exclusión de lo femenino, al homologar la humanidad con el hombre. Por eso, aboga por el término de Eleonor Roosvelt, derechos humanos, "que abarca los dos géneros". De allí afirma: "los derechos humanos surgen de los esfuerzos por cambiar de manera sustancial esas condiciones genéricas entre mujeres y hombres, y sus relaciones sociales" (2012: 17) .

Karina Bidaseca (2010) complejiza más la problemática, en el ámbito latinoamericano, al hablar de "colonialidad del género" como nueva episteme que permite comprender la vida de las mujeres de color latinoamericanas. Enjuicia las teorías feministas blancas hegemónicas que interpretan las prácticas culturales de las "mujeres subalternas como residuos arcaicos y como inmaduras para la praxis política". Su planteamiento es tanto más pertinente cuanto que ilumina

Fusionando ambas posiciones, diremos que el negro es víctima de una subordinación social (esclavizado y subvalorado por el color) que impacta en su condición económica (empobrecido y marginado).

4. La antropóloga muestra además las estrategias del feminismo latinoamericano frente al sujeto opresor y patriarcal (el hombre) que ha dado nacimiento a sujetos minorizados, expropiados y oprimidos: "las mujeres comparten con otros sujetos su condición política de opresión y, con grandes dificultades para ser reconocidas como pares y legítimas, han confluido con pueblos indígenas, homosexuales, comunidades negras y otras comunidades nacionales, y con grupos juveniles, entre otros, en la crítica política a las opresiones de género, de clase, étnica, racista y etaria: han puesto en crisis el principio ideológico legitimador del orden enajenado que consiste en considerar naturalmente desiguales a quienes sólo son diferentes y han decidido eliminar la desigualdad" (18). 
nuestra idea ya que muestra que a los obstáculos de "mujer" y "negra" se añade la "minoría" (como en el caso de las indígenas). Su expresión "negritud femenina" viene a reformular la esencia de este trabajo, así como su postulado feminista que enuncia que "desde la posición histórica de ser mujer y negra, un feminismo negro en las sociedades latinoamericanas deben enfrentar la racialización del sexo y la sexualización de la raza" (2012: 9). Desde esta perspectiva hablaremos de los conceptos de "género" y "negritud" en nuestro estudio, es decir todo lo relativo a la mujer de color en la Argentina del S. XIX.

Ahora bien, el mito de la mujer como "ángel del hogar" (enunciado por Nash), que era el "estandarte del pensamiento burgués europeo y rioplatense" (Coromina 2006:14), fomentará una estructura bipolar y un "bimorfismo sexual" de la sociedad argentina materializada por una nítida bipolarización de la vida pública y de la vida privada ${ }^{5}$. Además, en el escenario político argentino, sobre las condiciones de la mujer, tanto liberales como conservadores consideraban que el mejor lugar para la mujer era la vida hogareña, allí es donde servían a los maridos y se dedicaban a la buena crianza de la prole (Barrancos 2008: 34). Ese pensamiento unánime era la primera estampilla para la condición femenina y la primera forma de discriminación y marginación.

Ahora bien, qué decir de las afroargentinas, que eran "las mujeres más marginales de la sociedad" (Goldberg 2006: 229), mujeres socialmente destinadas a tareas siervas, que "trabajan principalmente como cocineras, lavanderas, costureras, planchadoras y amas de crías entre otras mil y una tareas domésticas y artesanales" (2006: 231). El ser esclava o descendiente y el ser mujer eran las condiciones de "subalternidad" que caracterizaban a la mujer negra y que influirán en su retrato en la literatura. Alejandro Solomianski da una perfecta ilustración de esta segregación por el gender incluso dentro de la "morenada" al afirmar que:

A mediados del siglo XIX, la presencia efectiva y pesadillesca para los letrados europeizantes de la mujer afroargentina torna su representación aún más irritante que la de los varones de piel oscura. Sarmiento puede hablar bien del coronel Barcela, Mitre puede inventar a su

5. Cristina Libereiro afirma a este respecto: "la nuestra, ha sido una sociedad heredadamente patriarcal desde la época colonial [...]. Desde los primeros tiempos de nuestra historia, se nos mostró aún desde la Escritura, la interpretación de la mujer como compañera y sólo 'compañera' del hombre, como 'ayuda', es decir, sin un rol propio y específico sino como 'apoyo' y 'complemento' del varón, sujeto único de la historia. Ella quedó confinada al ámbito del hogar como madre, esposa y reproductora de los valores sociales planteados desde el patriarcado. Lo privado le pertenece, mientras lo público, la política y el manejo de la economía fueron siempre campo privado del hombre" (1999: 79-80). 
Falucho, pero no hay representaciones positivas de las mujeres negras, ni siquiera como objetos sexuales, hasta unas cuantas décadas más tarde (2003:110).

Esta afirmación muestra no sólo la discriminación por el género sino también la visión de la mujer negra condicionada por su "afiliación" política. Como veremos más tarde con Amalia y El matadero, la mujer negra viene retratada entre antirrosismo y racismo. Les intelectuales que se oponían a Rosas y que denunciaban la "invasión africana" del escenario político veían en las mujeres negras las secretas aliadas del dictador, por lo que su retrato insinúa cierta coloración política.

Así, en los tres relatos que vamos a estudiar, considerados como los "grandes clásicos del siglo XIX", las "ficciones fundacionales", "textos surcados o, mejor aún, invadidos por afroargentinos" (Solomianski 2003: 17-18), la mujer negra viene representada desde varios ámbitos. En Amalia (1851) de Mármol, la narrativa está ambientada en la esfera doméstica-política (el hogar bajo el rosismo); en El matadero (1939-1940), que comparte el mismo contexto antirrosista, los personajes femeninos negros actúan desde el área laboral del matadero; y en Martín Fierro (1872-1879) la mujer negra aparece en el dominio cultural-folclórico (el baile) ${ }^{6}$. Proponemos un análisis de cada obra para mejor reflejar las diversas imágenes de sus personajes.

\section{Amalia: entre el hogar y la vida política}

Considerado como un "folletín de aventuras truculentas que transcurren en Buenos Aires durante los últimos años de la tiranía de Rosas" (Anderson Imbert y Florit 1960: 257), Amalia es uno de los relatos con mayor presencia de afrodescendientes. Este protagonismo de los negros en la obra es el reflejo de la coyuntura política y cultural durante la gobernación de Rosas. En efecto, la época rosista constituye la eclosión "política" de los negros argentinos. El boom de la población negra en aquel entonces y su "intrusión" en la esfera política al servicio del dictador (sobre todo con las mujeres desde el hogar) habían fomentado una notoria revalorización (y también enemistad) de la afroargentinidad. A nivel cultural, bajo la directa protección de Rosas, el candombe resucitaría y viviría su mayor apogeo (Goldberg 2006: 232). Noberto Pablo Cirio relaciona este

6. En la lista debería figurar Facundo de Sarmiento donde lo negro viene a ser componente de la barbarie, pero hemos querido concentrarnos en los relatos en los que hay más presencia y protagonismo de la mujer negra. 
auge cultural afro con el rosismo añadiendo que "el favoritismo que los negros tuvieron durante el periodo rosista por parte del poder, cuando hasta el mismo Rosas y su hija Manuelita asistían a sus candombes, es tópico discursivo que se ancla en el pasado para evocar tiempos de esplendor (2006: 32). Así, dicha relación entre Rosas y los afroargentinos había creado una secreta identidad entre "cultura popular", "negritud" y "rosismo" (Solomianski 2003: 104).

Ahora bien, las imágenes que se desprenden de la representación de la mujer negra en Amalia, y marcadamente teñidas por un acérrimo antirrosismo, son las de delatora y traidora. En efecto, sirvientas, las mujeres hacían de espías para el Gobernador. El chivatazo se había convertido en la principal arma de lucha contra los Unitarios y eran las mujeres las que desempeñaban esa labor. Afirma el narrador: "los negros, pero con especialidad las mujeres de ese color, fueron los principales órganos de delación que tuvo Rosas" (Mármol 2010: 721).

Sacar información de los adversarios políticos o /y "vender" a sus amos eran el quehacer diario de las sirvientas; actividades que ejercían devotamente y coordenadas por los familiares del dictador o por él mismo. Las casas se convertían en escenarios políticos por excelencia (esfumándose así las fronteras divisorias entre vida pública y vida privada) y el espionaje en el nuevo oficio de las negras. Entre los ejemplos, podemos añadir el de la negra que trabaja en la casa vecina de la de Amalia y que viene para darle una información capital para el desarrollo de la narración y para la causa federal. Dicha escena muestra cómo salió de la casa de Doña María y el sentimiento de satisfacción que la invadía: "la negra salió muy contenta de haber prestado un servicio a la santa causa de negros y blancos, y por haber hablado con la hermana política de Su Excelencia, el padre de la Federación" (418). Esta mujer negra ha venido para informar a Doña María de la presencia de un hombre extraño, que no lleva la Divisa y los colores de la Federación, en la casa de Amalia y le cuenta que: "va casi siempre un mozo que dicen que es primo de la unitaria; y estos meses pasados iba casi todos los días el médico Alcorta, por eso le dije a su merced que allí había algún enfermo" (417).

Ese activismo político convertirá a las mujeres negras en blanco de los intelectuales (que mayoritariamente encarnaban las ideas del unitarismo y algunas directamente víctimas del régimen dictatorial) particularmente el autor de Amalia $^{7}$. El retrato hecho de ellas está cargado de resentimiento político, lo

7. En su oposición al régimen de Rosas, José Mármol había sufrido muchos encarcelamientos y persecuciones. Enrique Anderson Imbert y Eugenio Florit sostienen, a este respecto, que José Mármol, el autor de Amalia, "escribió sus primeros versos en la pared del calabozo donde Rosas lo había engrillado en 1839: el énfasis con que él contaba y una y otra vez esa circunstancia fue típicamente romántico: la 
que hace que la imagen que reflejan sea siempre negativa. La descripción que el narrador hace de la negra cuando entra en la casa de Doña María puede ilustrar esa representación despreciativa de esta clase: "un minuto después entró a la alcoba una negrilla de dieciocho o veinte años, rotosa y sucia" (416).

La delación era, pues, la etiqueta que identificaba a la mujer negra, una mancha que ensuciaba una reputación ya mancillada por la esclavitud. Lea Geler, que ha analizado la imagen de las afroporteñas reflejadas en los periódicos de los afrodescendientes, muestra cómo en tales tribunas (ejemplo de una editorial de la Juventud) se confirman el estigma, la desconfianza y los prejuicios que se suponían que caían en estas mujeres quienes, además de ser pobres, de encargarse de los oficios considerados más bajos de la ciudad y de tener modales "impropios", eran históricamente consideradas como las aliadas del gobernador y también peligrosas delatoras de las familias opositoras al régimen de Rosas (2010: 179). Es en este sentido que hablamos de "negritud y género". La relación "mujer" = "negra" = "oficio sucio", desde la intelectualidad unitaria argentina, viene a reflejar la "posición subalterna" de la que habla Juan Zevallos y sobre todo cierta "opresión de género" por un "sujeto opresor" como quiere Lagarde. La mujer negra encajaría en lo que Lagarde llama "sujetos minorizados" que representan, desde la óptica de Mármol, la bajeza social con la delación y el chivatazo

José Mármol nos ha mostrado en Amalia el sitio y la situación de la mujer negra, una delatora y traidora empleada en las casas, en las que trabaja contra el amo y para el dictador. Sin embargo, otra imagen positiva puede desprenderse de esta representación, y es el compromiso, la determinación de dichas mujeres de entregarse fielmente a un oficio que les procuraba reconocimiento desde lo más alto del poder. El apoyo de Rosas, cuya contraparte era la delación, puede leerse como un trato entre el Gobernador y esa clase, un trato hecho en el que cada parte veía su cuenta y cumplirlo era como un deber de cada uno $^{8}$. Alejandro Solomianski habla de valentía de estas mujeres tan resueltas a luchar por lo que socialmente las beneficiaba y en compañía de sus hombres

tiranía de Rosas. Cuando cayó Rosas, el poeta enmudeció" (1960: 256). De allí se puede comprender perfectamente que sienta rencor para con este régimen y sobre todo para con los que lo apoyaban como los negros y las negras.

8. Eugenia Faué analiza este "contrato" y afirma a este respecto: "Rosas, rubio y de ojos celestes, se complacía en la asistencia de las festividades negras junto a su hija Manuelita. El carnaval salió del barrio del Mondongo, del tercer patio, y del arrabal hacia el centro de Buenos Aires. Dicen sus detractores de Juan Manuel que ese reconocimiento no era sino una mascarada proselitista del tirano para encubrir el espionaje doméstico que los negros tributaban ingenuamente como contraprestación de tal reconocimiento" (2006: 66). 
(2003: 152). Así, detrás de esta mirada desdeñosa se escondía una virtud que encarnaban esas mujeres, una misma duplicidad que veremos a continuación en El matadero.

\section{El matadero: racismo y antirrosismo en el ámbito laboral}

Otra víctima del rosismo, Echeverría construye una narración en la que la mujer negra está en la periferia de lo humano. Escrita en la cuaresma de 1839, la novela, como Amalia, hace un juicio de la mujer negra desde el banquillo político. El retrato que se hace de las "negrillas" no es más que el reflejo de una virulencia antirrosista que el autor exterioriza en dicho texto. La imagen no puede ser sino degradante. Es lo que constata Alejandro Solomianski para quien, en El Matadero, el mundo negro viene "descrito de manera irónica, despectiva y resentida" (2003:28).

La primera aparición de los personajes refleja una categorización y catalogación de las negras entre los animales: habitantes que han elegido feudo en el matadero y que han sido diezmados por la hambruna o han abandonado el lugar:

\footnotetext{
No quedó en el matadero ni un solo ratón vivo de muchos millares que allí tenían albergue. Todos murieron o de hambre o ahogados en sus cuevas por la incesante lluvia. Multitudes de negras rebusconas de achuras, como los caranchos de presa, se desbandaron por la ciudad como otras tantas harpías prontas a devorar cuanto hallaran de comible. Las gaviotas y los perros, inseparables rivales suyos en el matadero, emigraron en busca de alimento animal (Echeverría 1990: 94).
}

La mujer negra ubicada entre ratones, caranchos harpías, gaviotas, perros (sus vecinos y rivales) pierde no sólo su feminidad sino también su humanidad. Echeverría nos pinta un ser excluido de la comunidad humana utilizando un vocabulario más cerca del mundo animal "devorar", "desbandar" "rebuscar". Este retrato, que es el primero en la obra, deja ver un prejuicio y augurio de lo que será la mujer negra en el resto del relato. A esta animalización se añade lo que podríamos llamar la "masculinización" de la mujer negra (que era sin duda muy mala imagen) por compartir el matadero (un espacio público diferente del espacio doméstico reservado a la mujer) con los hombres. En la descripción siguiente, el autor recurre otra vez al vocabulario y el mundo animal para hablar de las mujeres negras: 
En torno de cada res resaltaba un grupo de figuras humanas de tez y raza distintas. La figura más prominente de cada grupo era el carnicero con el cuchillo en mano, brazo y pecho desnudos, cabello largo y revuelto, camisa y chiripá y rostro embadurnado de sangre. A sus espaldas se rebullían, caracoleando y siguiendo los movimientos, una comparsa de muchachos, de negras y mulatas achuradoras, cuya fealdad trasuntaba las harpías de la fábula, y, entremezclados con ellas, algunos enormes mastines que olfateaban, gruñían o se daban de tarascones por la presa (100).

La imagen que Echeverría quiere enseñar de las mujeres negras es clara: animales buscavidas que invaden el matadero y compiten con los pequeños predadores las entrañas de las reses $u$ otros pedazos de carnes. El siguiente cuadro que nos dibuja constituye la cima de su intención discriminatoria:

\begin{abstract}
Hacia otra parte, entre tanto, dos africanas llevaban arrastrando las entrañas de un animal; allá, una mulata se alejaba con un ovillo de tripas y resbalando de repente sobre un charco de sangre, caía a plomo, cubriendo con su cuerpo la codiciada presa. Acullá se veían acurrucadas en hileras cuatrocientas negras destejiendo sobre las faldas el ovillo y arrancando uno a uno los sebitos que el avaro cuchillo del carnicero había dejado en la tripa como rezagados, al paso que otras vaciaban panzas y vejigas y las henchían de aire de sus pulmones para depositar en ellas, luego de secas, achuras (102).
\end{abstract}

Esa visión prototípica de la mujer negra "más cerca de la animalidad que de la razón" (Gómez Nadal 2015: 34) es la que caracteriza a la mujer "pintada" en El matadero. El hecho de sacar a la mujer negra de su "hábitat natural" (el hogar, la vida privada), (a diferencia de Mármol en Amalia), para arrojarla en un mundo de matanza y de sangre, en el que lo femenino se esfuma en la bestialidad, es una clara manifestación de una intención de despojarle de su femineidad y hasta su humanidad. La visión acertada de Irene Coromina es una perfecta ilustración:

En El matadero, las únicas mujeres presentes son las 'negras achuradoras' que participan activamente en la descuartización de las reses. Echeverría las describe como 'caranchos de presa' y 'harpías', ya que rivalizan con las gaviotas y los perros en busca de achuras. Estas mujeres contribuyen a la atmósfera violenta e inmunda del matadero. Todas ellas son viejas, feas y vulgares; el matadero no es un espacio doméstico, por lo tanto no hay lugar para la femineidad idealizada allí. No hay esposas, no hay madres en este texto. Hay sólo una masa informe e ignorante (hombres y mujeres) que mantiene en el poder a Rosas. Las negras se sitúan claramente al margen del ideal (2006: 15). 
Echeverría describe a la mujer negra entre la miseria social y el rencor político y le asigna una imagen desdeñosa desde un mundo en el que la feminidad no tiene cabida. Así, Amalia participa en la "profundización de las subalternidades", como diría Karina Bidaseca (2012), materializada por el ser mujer, afro, pobre, y animalizada; y añade, retomando a Gayatri Spivak, que cuando el subalterno es mujer, su destino se encuentra todavía más a oscuras.

Sin embargo, detrás de este intento de estigmatizar, se cuela una imagen positiva de la mujer negra: una gran trabajadora que intenta sobrevivir en un mundo de marginación social y de crisis económica. Las actividades de las negras, que descuartizan la carne, que compiten con animales y varones, son una forma de independencia económica que ellas han querido cultivar, a pesar de este lugar inhóspito para ellas. Más aún, una nueva lectura puede desprenderse en este ámbito laboral: la desmitificación del mito de la mujer como "ángel del hogar", de la mujer como incapaz de desempeñar algo en el espacio público. La teoría de Marcela Lagarde sobre la "autonomía de las mujeres" encontraría aquí una ilustración pertinente. En efecto, las actividades laborales de las mujeres negras desbaratan incluso la noción taxativa de género o de "sexo débil" y la historia les ha dado razón ya que hoy ya está o se está desvaneciendo la bipolarización del mundo laboral (por el sexo). Entre los pocos críticos que han resaltado esa laboriosidad como signo de revalorización de su imagen (algo que ha escapado acaso a Echeverría en su obsesión de descreditar a esa clase trabajadora), citaremos a Solomianski quien destaca sutilmente que:

Irónicamente, más allá del repelente racismo del texto en el que el narrador se da la satisfacción simbólica de hacer caer a una trabajadora ('mulata') en un charco de sangre, no puede dejar de percibirse la organizada y prolija laboriosidad de estas mujeres, la considerable dimensión económica de su práctica laboral, las pésimas condiciones de trabajo y el origen afroargentino de las más típicamente parrillada rioplatense (2003: 128-129).

El retrato de la mujer negra dentro del conflicto entre unitarios y federales en El matadero (y también en Amalia) ha impedido apreciar de manera explícita su imagen justa y equitativa (con altibajos). Considerada indirectamente como adversaria y hasta enemiga política, no podría esperarse otra cosa sino una valoración negativa por su sexo y su color. Este racismo y esta animalización se reproducirán también en el Martín Fierro de Hernández. 


\section{Martín Fierro: racismo en el ámbito folclórico}

Si Amalia y El matadero presentan a los negros bajo Rosas, en Martín Fierro los negros aparecen en espacios socioculturales o folclóricos: el baile, las pulperías y el contrapunto (negro cantor). José Hernández hace la representación de una familia negra desde la jerarquización de la sociedad argentina. La obra propone una narración de gauchos y negros bajo Sarmiento y, a diferencia de Amalia ${ }^{9}$, presenta un cuadro más aceptable de la afroargentinidad a pesar, claro, del racismo existente. La presencia de los negros es determinante ya que ellos abren verdaderamente el relato (con la muerte del negro matado por el gaucho) y lo cierran (con la payada vengadora de su hermano moreno). Hernández, que se opone a Sarmiento ${ }^{10}$ sobre la consideración del gaucho en la encarnizada lucha entre "gauchophiles et gauchophobes" (Cymerman 1997), resalta la figura del "paisano" retratando su vida, sus sufrimientos, sus aventuras, su convivencia con los demás grupos: los negros, los indios, los extranjeros y las autoridades policiales y judiciales.

Tocante a la figura femenina negra, viene protagonizada por la amante del negro asesinado por Martín Fierro al principio de la historia. El autor muestra, a través de los juicios y prejuicios de Martín Fierro, la imagen de la mujer negra en un contexto en que, en las sociedades latinoamericanas, se había creado "un sistema de jerarquías sociales basadas en pirámides raciales, en el que el blanco y el mestizo se ubicaban en la escala superior y gozaban de privilegios ciudadanos, mientras que en la inferior se situaban los indígenas y los esclavos africanos y sus descendientes (Yao 2016:17). Pero dicha clasificación, viene incluso repetida y rediseñada por el propio gaucho Martín Fierro cuando se dirige a la mujer negra acompañada de su amante en estas palaras: "Negra linda' dije...yo, / 'me gusta... pa la corona', / y me puse a talariar / esta coplita fregona: / 'A los blancos hizo Dios, / a los mulatos San Pedro / a los negros hizo el diablo para tizón del infierno"" (Hernández 1994: 99).

9. Alejandro Solomianski compara las dos obras, destacando una "oposición estética, política y ética", y afirma: "si en Amalia el racismo más repugnante, que llega a formularse de manera explícita, presupone el marco representacional destinado a crear di(re)ferencia estrepitosa de la 'negritud', por su parte sería de esperarse en el Martín Fierro una inversión de dicha lógica de representación, que al menos otorgase a la negritud el atributo de la nacionalidad" (154-155).

10. Sarmiento ubica al gaucho dentro lo que ha llamado Barbarie. En Facundo, describe al "gaucho malo" como un "outlaw", "un misántropo particular", "un hombre que vive divorciado con la sociedad, proscrito por las leyes", "el salvaje de color blanco", "el personaje misterioso que vive de perdices y mulitas" (2005: 88-89). En fin, todo un rosario de rasgos negativos que convierten al "guapo" como el prototipo de la barbarie. 
La provocación de Martín Fierro, además de esta jerarquización racista que propone, y que ejemplifica la noción de subalternidad como "rango inferior" enunciada en este trabajo, va dirigida primero a la mujer negra y permite ver la primera imagen que Hernández refleja en la obra. Dice el gaucho: "como nunca, en la ocasión / por peliar me dio la tranca, / y la emprendí con un negro / que trujo a una negra en ancas / Al ver llegar la morena / que no hacía caso de naides / le dije con la mamúa: "Va... ca... yendo gente al baile"" (99). Fierro, en un sutil juego lingüístico, compara a la mujer negra con una "vaca". Esa consideración no es fortuita sino que traduce todo un estereotipo común sobre la mujer afro considerada, por su corpulencia, como una vaca. La animalización de la que hemos hablado con El matadero de Echeverría viene a reproducirse, aunque en un contexto diferente. Pero lo que importa es esa visión deshumanizadora común que sitúa a la afroargentinidad femenina en el bestiario. Este otro ejemplo, en el que Martín Fierro equipara a la negra con una fiera, tras matar a su compañero moreno, es otra muestra de esta animalización: "En esto la negra vino, / con los ojos como ají, / y empezó la pobre allí / a bramar como una loba" (103). En este último ejemplo, Fierro recidiva en su agresión verbal hacia la mujer cuando esta entra en el baile: "Y dentró al baile muy tiesa / con más cola como una zorra / haciendo blanquiar los dientes / lo mesmo que mazamorra" (99).

Aunque el vocabulario animal está muy presente en el lenguaje gaucho a la hora de comparar, aquí hay una voluntad manifiesta de herir, de hacer daño a la mujer. Las palabras de Fierro no son más que insultos dirigidos a una mujer inofensiva. Así, la mujer negra que aparece en Martín Fierro está representada por un doble juicio que corresponde con su género y negritud: negra como creación del "diablo para tizón del infierno", y mujer animalizada: "vaca", "zorra" y "loba". José Hernández plasma en este texto el imaginario colectivo en el que se desprende "una antojadiza superioridad del blanco" (González Lanuza 1981: 141). La visión de la mujer, esta vez condicionada por la clasificación racial, conlleva siempre una estigmatización deshumanizante. Esta idea de "subordinación social" propuesta por Williams como esencia del subalternismo, viene a caracterizar la relación que el personaje Fierro tiene del negro (última escala de la sociedad).

Sin embargo, detrás de este retrato, se esconden grandes virtudes que sobresalen con la actuación de la mujer negra: el orgullo y la inteligencia. En efecto, al presentar a la morena como que "no hacía caso de naides", Fierro insinúa, inconscientemente, el orgullo y la valentía que caracterizan a esa mujer, su carácter fuerte que reclama respecto y dignidad para la gente de color. Para 
John B. Hughes, "la figura gallarda de la mujer 'que no hacía caso a naides' nos impresiona y también al narrador que resuelve atacarla en su orgullo de mujer. Ella no es nada lerda en comprender y atacar otra vez" (1970:121). La inteligencia de la mujer también se desprende en su pronta respuesta guerrera en la que descifra el insulto de Fierro: "La negra entendió la cosa / y no tardó en contestarme, / mirandomé como a perro: "Más vaca será su madre" (Hernández, 1994: 99). Tales virtudes han sido también destacadas por Solomianski, quien confiesa: "me interesa destacar el orgullo y la dignidad de la negra, su rapidez mental, su autonomía, la 'superioridad' que adquiere en el momento de responder a ese gaucho borracho y pendenciero que en esa peripecia se configura como antihéroe" (159).

Ahora bien, para algunos críticos, si la obra refleja, al principio, algún racismo por la ofensa gratuita de Fierro al negro y a su mujer por su condición de negros (González Lanuza 1981: 141), también ofrece una reconciliación, "una mayor 'aprojimación' entre ellos, una amplia posibilidad de entendimiento por compartir, en lo esencial, una misma tabla de valores, al revés de lo señalado por indios y puebleros" (González Lanuza 1981: 142). Alejandro Solomianski rechaza que se hable de racismo del texto y considera que Hernández ha querido mostrar cómo el gaucho Fierro ha sido transformado en delincuente ${ }^{11}$. Es lo que parece decir John Hughes cuando afirma que "el negro pagó los crímenes de los otros, los jueces, los de la frontera, y todos los que habían victimizado a Martín Fierro. Ha escogido al negro porque es la única figura que puede considerar como inferior a él" (125). Pero de todos modos, si el texto no tiene intención racista, sí que refleja el pensamiento común de aquel entonces donde el negro está situado en la baja escala y, por consiguiente, era sistemáticamente discriminado. Y tocante a la mujer, su condición femenina le convierte en blanca fácil, porque es la primera a quien Fierro ofende por ser mujer y la palabra utilizada, "vaca", es un estereotipo directo asignado a la mujer negra.

Así, en los tres relatos, la representación de la mujer negra consiste en una escenificación de una víctima social y política. Por la alianza con el rosismo, viene retratada como delatora en Amalia y animales muertas de hambre en El matadero. En Martín Fierro, ella sirve de figurante para experimentar la

11. Hablando de la escena del asesino del negro por Fierro, reconoce: "algunos comentaristas ven en esta escena un cierto racismo por parte de José Hernández, lo cual es insostenible, o al menos por parte de su personaje, lo cual aunque discutible parece poco probable considerando el texto en su conjunto. En mi opinión, ésta es la escena en que el protagonista se hace delincuente como máxima victimización del sistema ya que 'el ser gaucho es un delito'. En todo caso es su máximo error y no sólo le acarreará más violencia y sufrimientos sino que transforma negativamente su identidad" (160). 
injusticia que cae sobre el gaucho víctima del sarmentismo. En todos los casos sale más parada por su color y su género.

\section{Conclusión}

En el mapa literario de la afroargentinidad, o mejor dicho con Karina Bidaseca de la "negritud femenina", que hemos trazado en este trabajo, hemos destacado una imagen despectiva de la mujer negra común en los relatos decimonónicos argentinos más representativos. Tanto Amalia y El matadero como Martín Fierro nos han representado a un sujeto marginado desempeñando labores viles (política y económicamente) y más cerca del animal que del humano. La imagen de la mujer negra en esas narraciones fundacionales está íntimamente ligada a una cosmovisión política (anti-Rosas y anti-Sarmiento). José Mármol, Esteban Echeverría y José Hernández, en su combate político, han hecho una representación literaria de la mujer negra en la vida pública y privada, retrato en el que los presupuestos clasicistas, ideológicos y racistas han creado una imagen disforme de la negritud y del género, a pesar de las virtudes reales que destaca esta comunidad y que se esconden detrás de estos retratos. Pero ellos no hacen más que reflejar lo que hasta hoy impregna torpemente el imaginario colectivo: el binomio femenino-negro es una doble estigmatización y el ser negro en general es signo de alteridad y de subalternidad.

\section{Bibliografía}

ALABARCES, P. (2016). "Subalternidad, pos-decolonialidad y cultura popular: nuevas navegaciones en tiempos nacional-populares". Versión. Estudios de comunicación y Politica 37: 13-22. http://version.xoc.uam.mx.

BARRANCOS, D. (2011). "Mujer y ciudadanía en la Argentina”. Iberoamericana. Nordic Journal of Latin American and Caribbean Studies 41 (1-2):23-39.

BARRANCOS, D. (2008). Mujer, entre la casa y la plaza. Buenos Aires: Sudamericana.

CARILLA, E. (1973). La creación del Martín Fierro. Madrid: Gredos.

CIRIO, N. P. (2006). "La presencia del negro en grabaciones del tango y géneros afines" en Buenos Aires negra. Identidad y cultura. (Comp. L. Moranesa). Buenos Aires: Comisión para la Preservación del Patrimonio Histórico Cultural de la Ciudad de Buenos Aires: 25-48.

CORRÊA, Â. (2006). A los negros argentinos salud. Buenos Aires: Nuestra América. 
COROMINA, I. S. (2006). "La mujer en los escritos antirrosistas de Echeverría, Sarmiento, y Mármol”. Hispania 89 (1): 13-19.

BIDASECA, K. (2012). "Voces y luchas contemporáneas del feminismo negro. Corpolíticas de la violencia sexual racialda" en Afrodescendencia. Aproximaciones contemporáneas de América latina y el Caribe. Colección de ensayos del Centro de Información de las Naciones Unidas para México, Cuba y Rca. Dominicana, en el marco del Año Internacional de los Afrodescendientes, ONU, México, 2012. Disponible en: http://www.cinu. mx/AFRODESCENDENCIA.pdf.

BIDASECA, K. (2014). "Cartografía descoloniales de los feminismos del Sur”. Estudos Feministas, Florianópolis 22 (2): 585-591.

BIDASECA, K. y VAZQUEZ, V. (2010). I Jornada "Feminisimo, (Pos)colonialidad y Hegemonía. Descolonizando el feminismo desde y en América latina" organizado por el Programa "Pensamiento fronterizo y transfronterizo en los estudios feministas" (Instituto de Altos Estudios Sociales, UNSAM) y Glefas, 2010. http://pdfhumanidades.com/sites/default/files/apuntes/47\%20 -\%20Bidaseca.pdf.

ECHEVERRÍA, E. (1990). El matadero. La cautiva. (Ed. de Leonor Fleming). Madrid. Cátedra.

FAUÉ, M. E. (2006). "'Blanquitud' y 'negritud' en los registros literarios rioplatenses" en Buenos Aires negra. Identidad y cultura. (Comp. L. Moranesa). Buenos Aires: Comisión para la Preservación del Patrimonio Histórico Cultural de la Ciudad de Buenos Aires: 61-75.

FRIGERIO, A. (2006). “'Negros' y 'Blancos' en Buenos Aires: repensando las nuestras categorías raciales" en Buenos Aires negra. Identidad y cultura. (Comp. L. Moranesa). Buenos Aires: Comisión para la Preservación del Patrimonio Histórico Cultural de la Ciudad de Buenos Aires: 77-98.

GELER, L. (2010). Andares negros, caminos blancos. Afroporteños, Estado y Nación argentina a finales del siglo XIX. Rosario: Prohistoria.

GOLDBERG, M. B. (2010). "Afrosoldados de Buenos Aires en armas para defender a sus amos" en Negros de la Patria. Los afrosoldados en las luchas por la independencia en el antiguo Virreinato del Río de Plata. (Eds. S. C. Mallo e I. Telesca). Buenos Aires - Montevideo - México: SB: 39-63.

GOLDBERG, M. B. (2006). "Las mujeres africanas en el Río de la Plata: Organización comunitaria y conservación del patrimonio cultural" en Buenos Aires negra. Identidad y cultura. (Comp. L. Moranesa). Buenos Aires: Comisión para la Preservación del Patrimonio Histórico Cultural de la Ciudad de Buenos Aires: 229-235. 
GOMES, M. V. (2002). "La presencia negroafricana en Argentina. Pasado y permanencia" http://www.nacionmulticultural.unam.mx/ reconocimientopueblosnegros/docs/304.pdf (Acceso 16 octubre 2018).

GONZÁLEZ LANUZA, E. (1981). Temas del Martín Fierro. Buenos Aires: Academia Argentina de Letras.

HERNÁNDEZ, J. (1994). Martín Fierro. (Ed. de Ángel J. Battistessa). Madrid: Clásicos Castalia.

HUGHES, J. B. (1970). Arte y sentido de Martín Fierro. Madrid: Castalia.

LAGARDE DE LOS RIOS, M. (2012). El feminismo en mi vida. Hitos, claves y topías. México: Gobierno de la Ciudad de México Instituto de las Mujeres del Distrito Federal.

LAGARDE DE LOS RIOS, M. "Claves feministas para el poder y la autonomía de las mujeres". http:/www.caladona.org/grups/uploads/2013/04/clavesfeministaspara-el-poderio-y-autonomia_mlagarde.pdf

LIBOREIRO, M. C. (1999). No hay negros argentinos? Buenos Aires: Dunken. MÁRMOL, J. (2010). Amalia. (Ed. de T. Fernández). Madrid: Cátedra.

NASH, M. (2006). Rojas: las mujeres republicanas en la Guerra Civil. Madrid: Taurus.

PÉREZ VALDÉS, I. (1978). "Papel del negro en la emancipación de América Latina" en Négritude et Amérique Latine (Colloque de Dakar: 7 au 12 janvier 1974) (Coord. R. Durand). Dakar: Les Nouvelles Editions Africaines: 453460.

SARMIENTO, D. F. (2005). Facundo. Civilización y Barbarie. (Ed. R. Yahni). Madrid: Cátedra.

SOLOMIANSKI, A. (2003). Identidades secretas: la negritud argentina. Rosario: Beatriz Viterbo.

SPIVAK, G. C. (1985). "Estudios de la Subalternidad: Deconstruyendo la Historiografía" (Traducción de Ana Rebeca Prada y Silvia Rivera Cusicanqui del artículo "Subaltern Studies: Deconstructing Historiography" en Subaltern Studies IV: Writings an South Asian History and Society, (Ed. Ranajit Guha). Delhi: Oxford University Press: 330-363.

TOUCHARD, J. (1966). La république argentine. Paris: Presse Universitaire de France.

WILLIAMS, G., (2008). "La deconstrucción y los estudios subalternos, o una llave de tuerca en la línea de montaje latinoamericanista" en Treinta años de estudios literarios/culturales latinoamericanistas en Estados Unidos: memorias, testimonios, reflexiones críticas (Ed. Hernan Vidal). Pittsburgh: Instituto Internacional de Literatura Iberoamericana, Universidad de 
Pittsburgh. https://es.scribd.com/document/156652538/Gareth-Williams-LaDesconstruccion-y-Los-Estudios-Subalternos.

YAO, J. A. (2016). In-visibles. Percepciones y autopercepciones de los argentinos de origen africano. Madrid: Literatura Comunicación.

YAO, J. A. (2014). Afrodescendientes en América. Madrid: Mundo Negro.

YAO, J. A. (2012). "Negros en Argentina: integración e identidad". https:// journals.openedition.org/amnis/183 (Acceso 15 octubre 2018).

ZEVALLOS, J. (2001). "Baile, comida y música en la construcción de una identidad cultural subalterna andina en el exilio norteamericano" en Convergencia de tiempos: estudios subalternos/contextos latinoamericanos estado cultura, subalternidad. (Ed. Ileana Rodríguez). Amsterdam, Atlanta: Recopy: 365-380. 